\title{
Epigenetically silenced PTPRO functions as a prognostic marker and tumor suppressor in human lung squamous cell carcinoma
}

\author{
FEI MING and QIANQIANG SUN \\ Department of Thoracic Surgery, Hubei Cancer Hospital, Wuhan, Hubei 430000, P.R. China
}

Received April 11, 2016; Accepted March 16, 2017

DOI: $10.3892 / \mathrm{mmr} .2017 .6665$

\begin{abstract}
Protein tyrosine phosphatase receptor-type $\mathrm{O}$ (PTPRO), a member of the PTP family, has been frequently reported as potential tumor suppressor in many types of cancer. However, the exact function of PTPRO in lung squamous cell carcinoma (LSCC) remains unclear. Bisulfite sequencing and methylation specific polymerase chain reaction (PCR) were used to identify the methylation status of PTPRO in LSCC cells, and quantitative methylation specific PCR was used to evaluate the methylation levels of PTPRO in LSCC patients. Stably expressing $P T P R O$ vectors were constructed and transfected into H520 and SK-MES-1 cells, followed by MTT and colony formation assays, and analysis of tumor weight and volume in in vivo mouse xenograft models. The present study demonstrated that the $\mathrm{CpG}$ island of PTPRO exon 1 was obviously hypermethylated in LSCC cells and tissues. The mRNA expression of PTPRO could be restored by treatment with a demethylation agent. Increased methylation and decreased mRNA levels of PTPRO were observed in LSCC samples compared with adjacent healthy tissues, and were associated with poor prognosis of patients. The mRNA expression of PTPRO was negatively correlated with its methylation level in tumors. Functionally, ectopic PTPRO expression in LSCC cells significantly inhibited the proliferation rates, and colony formation, in comparison with control and non-transfected cells. In vivo assays confirmed the inhibitory effect of PTPRO on LSCC cell growth. In conclusion, these data provided evidence that epigenetic regulation of PTPRO impairs its tumor suppressor role in LSCC, and restoration of PTPRO may be a potential therapeutic strategy.
\end{abstract}

Correspondence to: Dr Qianqiang Sun, Department of Thoracic Surgery, Hubei Cancer Hospital, 116 South Zhuo Daoquan Road, Hongshan, Wuhan, Hubei 430000, P.R. China

E-mail: sunqqchina@126.com

Key words: protein tyrosine phosphatase receptor-type O, methylation, cell proliferation, prognosis, lung squamous cell carcinoma

\section{Introduction}

Lung cancer is the most common malignancy and the leading cause of cancer-associated mortality worldwide, primarily in the form of squamous cell carcinoma $(1,2)$. Many cases are diagnosed at an advanced stage, which may be responsible for the poor prognosis in lung cancer patients. Thus, determining novel and effective therapeutic targets is indispensable for lung squamous cell carcinoma (LSCC) treatment, and may provide novel insights into carcinogenesis.

Carcinogenesis is a multistep progress. Tumor-suppressor genes or oncogenes serve critical roles in regulating tumor-associated biological process, including proliferation, apoptosis, migration and invasion (3-5). Previous studies have identified many classic tumor suppressor genes, including reversion-inducing-cysteine-rich protein with kazal motifs (RECK), breast cancer 1 (BRCA1) and Ras association domain family 1 isoform $\mathrm{A}$ (RASSF1A) (6-8). These genes were hypermethylated in various types of tumors and were involved in tumor-associated biological processes. For example, promoter methylation of RECK contributes to metastasis of osteosarcoma (9). BRCAl negatively mediates cell proliferation, and its mRNA levels were downregulated by methylation (10). The epigenetically inactivated RASSF1A gene was associated with poor prognosis and advanced tumor stage (11). Therefore, revealing the potential underlying mechanism and function of deregulated tumor-associated genes may have great benefit for the understanding of carcinogenesis. Protein tyrosine phosphatase receptor-type O (PTPRO) is a candidate tumor suppressor belonging to the protein tyrosine phosphatase (PTP) family, and is highly conserved in different species (12). Previous studies have reported that DNA methylation is involved in the regulation of PTPRO in hepatocellular carcinomas (13), lung cancer (14), chronic lymphocytic leukemia (15), esophageal squamous cell carcinoma (16) and colorectal cancer (17). Overexpression of PTPRO inhibits cell proliferation and promotes apoptosis in hepatocellular carcinoma and lymphoma $(18,19)$, while downregulation of $P T P R O$ is associated with metastases in breast cancer (20). PTPRO regulates mammary epithelial transformation via directly targeting the receptor tyrosine kinase ErbB2/human epidermal growth factor receptor 2 (21). Although these studies suggested the candidate tumor suppressor role of $P T P R O$, the expression and biological function of PTPRO in LSCC remains to be fully elucidated. 
The present study assessed the methylation and expression of PTPRO in LSCC cells and tissues, and the effect of overexpression of $P T P R O$ on tumor growth. The $\mathrm{CpG}$ island of PTPRO exon 1 was hypermethylated in H520 and SK-MES-1 cells. In LSCC patients, the significantly higher methylation levels of PPTPRO was correlated with its decreased mRNA levels. Furthermore, upregulation of PTPRO significantly inhibited cell proliferation and colony formation in vitro, and the tumorigenicity of H520 cells in vivo. These data suggested that epigenetic regulation of $P T P R O$ expression is likely to be involved in the progression of LSCC.

\section{Materials and methods}

Tissue samples. Primary tumors and corresponding adjacent healthy tissues were obtained from 65 patients, including 40 men and 25 women, with a mean age 61.7 years, who were diagnosed in Department of Thoracic Surgery, Hubei Cancer Hospital (Wuhan, China) between March 2010 and July 2011. All the tumors used in this study were squamous cell carcinoma, and tumor stages were confirmed by pathologists according to the criterion of Union for International Cancer Control. The clinical characteristics were obtained from medical records. This study was approved by the ethical committees of Hubei Cancer Hospital and written informed consent was obtained prior to surgery. All tissue specimens were surgically resected and immediately flash-frozen in liquid nitrogen, and stored at $-80^{\circ} \mathrm{C}$.

Cell lines and cDNA transfection. The H520 and SK-MES-1 LSCC cell lines and the BEAS-2B healthy human bronchial epithelial cell line were obtained from the American Type Culture Collection (Manassas, VA, USA) and cultured in the conditions as recommended (22). The cells were maintained in RPMI-1640 medium (Invitrogen; Thermo Fisher Scientific, Inc., Waltham, MA, USA) supplemented with $10 \%$ fetal bovine serum and $100 \mathrm{U} / \mathrm{ml}$ penicillin sodium at $37^{\circ} \mathrm{C}$ in an humidified atmosphere of $5 \% \mathrm{CO}_{2}$. To construct a vector stably expressing PTPRO, a pcDNA 3.1-Hemagglutinin A (HA)-tagged vector (Invitrogen; Thermo Fisher Scientific, Inc.) was purchased and used in this study. The cDNA encoding the complete coding region of human PTPRO cDNA was obtained from GeneBank (NM_030667.2). The HA label was introduced to protein $\mathrm{C}$ in the vector, and the E.coli strain of DH5a was also preserved in a laboratory at Hubei Cancer Hospital. A pcDNA-PTPRO-HA expression vector was established using a traditional method (23).

DNA extraction and methylation analysis. Total amounts of DNA $(2 \mu \mathrm{g})$ were extracted from cells and tissues using a DNeasy Blood \& Tissue kit (Qiagen GmbH, Germany) according to manufacturer's protocol. The quantity of DNA was tested by a NanoDrop spectrophotometer (Thermo Fisher Scientific, Inc.), and stored at $-80^{\circ} \mathrm{C}$ until use. All DNA samples were treated using an EpiTect Bisulfite kit (Qiagen $\mathrm{GmbH}$ ), and converted-DNA was used as a template in next step analysis. For bisulfite sequencing-polymerase chain reaction (BSP-PCR) analysis, the PCR reaction was conducted in $50 \mu \mathrm{l}$ solution containing converted-DNA (200 ng), dNTP (200 nM for each), forward and reverse primers (50 pM), and Taq DNA Polymerase (2.5 U; Thermo Fisher Scientific, Inc.). The $4 \mu \mathrm{l}$ PCR products $(0.1 \mu \mathrm{g} / \mu \mathrm{l})$ were ligated into the PMD18T vector. Recombinant vectors were then transformed to $E$. coli and the positive colonies were selected for sequencing. As inactivation of tumor suppressor genes may occur via hypermethylation of $\mathrm{CpG}$ islands upstream of the transcription start site, the present study selected a target region spanning from -405 to -74 (containing $23 \mathrm{CpG}$ sites) in the BSP analysis, and the primers for PTPRO (forward: 5'-GAG GTTGTTGTTATTTTATGGG-3'; reverse: 5'-TAAAACTAC AACCTCAAACCCT-3') were used. Methylation specific PCR (MSP) assays were performed using a Techne-512 system (Techne, Staffordshire, UK) and included an initial incubation at $95^{\circ} \mathrm{C}$ for $5 \mathrm{~min}$, followed by 40 cycles of denaturation at $95^{\circ} \mathrm{C}$ for $30 \mathrm{sec}$, annealing at $56^{\circ} \mathrm{C}$ for $20 \mathrm{sec}$, extension at $72^{\circ} \mathrm{C}$ for $20 \mathrm{sec}$ and a final extension step at $72^{\circ} \mathrm{C}$ for $10 \mathrm{~min}$. One pair of primers for methylated PTPRO (forward: $5^{\prime}-\mathrm{TGT}$ TGTTAGAGGATTACGGC-3'; reverse: 5'-CAAAAACGT ACCAAACGCTA-3') and unmethylated PTPRO (forward: 5'-TTTTGTTGTTAGAGGATTATGGT-3'; reverse: 5'-TCC AAAAACATACCAAACACTAC-3') were used to amplify methylation and unmethylation alleles of PTPRO, respectively. Quantitative (Q) MSP was performed to detect the methylation levels of $P T P R O$ in tumors and matched healthy tissue, and the quantity of methylated $P T P R O$ was normalized to $\beta$-actin. Briefly, $10 \mathrm{ng}$ bisulfite-coverted DNA was used in the QMSP assay in 384-well plates with a LightCycler480 system (Roche Diagnostics, Basel, Switzerland). The PCR reaction included an initial incubation at $95^{\circ} \mathrm{C}$ for $5 \mathrm{~min}$, followed by 45 cycles of denaturation at $95^{\circ} \mathrm{C}$ for $30 \mathrm{sec}, 58^{\circ} \mathrm{C}$ for $10 \mathrm{sec}, 72^{\circ} \mathrm{C}$ for $20 \mathrm{sec}$ and $80^{\circ} \mathrm{C}$ for $1 \mathrm{sec}$. Each plate consisted of clinical samples, water blanks and a positive control. Serial dilutions of the H520 PTPRO methylation-positive cell line were used for constructing the calibration curve. QMSP analyses yield values are expressed as ratios between two absolute measurements (PTPRO: $\beta$-actin x100) (24). Each sample was analyzed in duplicate.

5-Aza-2'-deoxycytidine (5-AZA) treatment. For the demethylation assay, $1 \times 10^{5}$ H520 and SK-MES-1 cells were seeded into 6-well plates, cultured for $24 \mathrm{~h}$ and treated with $0,2.5$ or $5 \mu \mathrm{M} 5$-AZA (Sigma-Aldrich; Merck KGaA, Darmstadt, Germany). Fresh medium containing 5-AZA was changed every $24 \mathrm{~h}$ for 3 days and the treated cells were harvested for reverse transcription-quantitative (RT-q) PCR analysis.

RNA extraction and RT-qPCR analysis. Total RNA was isolated from cells using TRIzol ${ }^{\circledR}$ regent (Invitrogen; Thermo Fisher Scientific, Inc.) according to the manufacturer's protocol. Total RNA was reverse transcribed into cDNA, and this procedure was performed once using the PrimeScript RT reagent kit (Takara Bio, Inc., Otsu, Japan), which was subsequently used for RT-qPCR analysis using an ABI 7500 fast Sequence Detector (ABI, Carlsbad, CA, USA). The reaction conditions were as follows: an initial predenaturation step at $95^{\circ} \mathrm{C}$ for $10 \mathrm{~min}$, followed by 40 cycles of denaturation at $95^{\circ} \mathrm{C}$ for $10 \mathrm{sec}$, annealing at $60^{\circ} \mathrm{C}$ for $20 \mathrm{sec}$ and extension at $72^{\circ} \mathrm{C}$ for $30 \mathrm{sec} . \beta$-actin served as the endogenous control for detection of mRNA expression levels (25). Relative quantification analysis was performed using the $2^{-\Delta \Delta C q}$ method (25). The following 
primers for PTPRO (NM_030667.2, transcript variant 1) were used: Forward, 5'-ACTGCCCCTTATCCACCTCA-3' and reverse, 5'-TGTTGCCCGAGGGAATTTCA-3'.

Cell proliferation and colony formation assays. Cell proliferation was assessed by MTT assay. H520 and SK-MES-1 cells were seeded into 96-well culture plates at a density of $1.5 \times 10^{3}$ per well. after 1-6 days, cells were incubated with $20 \mu \mathrm{l}$ MTT ( $5 \mathrm{mg} / \mathrm{ml}$, Sigma-Aldrich; Merck $\mathrm{KGaA}$ ) for $4 \mathrm{~h}$ at $37^{\circ} \mathrm{C}$. The cell medium was removed and $150 \mu$ l dimethyl sulfoxide was added to each well. The absorbance was measured at a wavelength of $490 \mathrm{~nm}$ using a microtiter plate reader (Tecan Schweiz AG, Männedorf, Switzerland). To investigate clonogenic ability, cells were transfected with PTRPO or an empty vector, and subsequently seeded into 6-well (200 cells per well) plates. The culture medium was replaced every 3 days. After 2 weeks, the medium was removed and the plates were washed twice using PBS. The colonies were fixed in methanol at $-20^{\circ} \mathrm{C}$ for $5 \mathrm{~min}$, stained with $0.1 \%$ crystal violet (Sigma-Aldrich; Merck $\mathrm{KGaA}$ ), and counted using an inverted microscope (Nikon Corporation, Tokyo, Japan) in five random fields.

Tumorigenicity analysis. Xenograft experiments were performed to evaluate the tumorigenicity of H520 cells transfected with PTPRO or an empty vector. Briefly, $1 \times 10^{7} \mathrm{H} 520$ cells resuspended in $200 \mu \mathrm{l}$ PBS were subcutaneously injected into the flanks of athymic nude male mice ( $n=5$; age, 4 weeks), which were obtained from the Type Culture Collection of the Chinese Academy of Sciences (Shanghai, China). Animal experiments were conducted in accordance with guidelines approved by the Institutional Animal Care and Use Committee of Hubei Cancer Hospital. The mice were maintained at a temperature of $18-22^{\circ} \mathrm{C}$ and humidity of 50-60\% under $12: 12 \mathrm{~h}$ light-dark cycle with had free access food and water. Each mouse was injected in left flank with the PTPRO vector, and in the right flank with the empty vector. A total of 28 days after injection, tumors were harvested, weighed and assayed for mRNA expression.

Western blot analysis. Equal amount of protein extracts were lysed using radioimmunoprecipitation assay lysis buffer (Sigma-Aldrich; Merck KGaA). Cells were centrifuged in a microcentrifuge at $12,000 \mathrm{x}$ g for $15 \mathrm{~min}$ at $4^{\circ} \mathrm{C}$ to collect the supernatant. Protein concentration was determined using a Bicinchoninic Acid Protein Assay kit (Pierce; Thermo Fisher Scientific, Inc.). A total of $30 \mu \mathrm{g}$ protein were separated by $10 \%$ SDS-PAGE and then transferred onto polyvinyl fluoride membranes (Merck KGaA). The membranes were blocked with 5\% fat-free milk in Tris-buffered saline for $1 \mathrm{~h}$, and incubated with anti-PTPRO (1:1,000; catalog no. sc-365354; Santa Cruz Biotechnology, Dallas, TX, USA) and anti- $\beta$-actin (1:2,000; catalog no. 4970, Cell Signaling Technology, Inc., Danvers, MA, USA) primary antibodies at $4^{\circ} \mathrm{C}$ overnight. The membranes were washed three times with Tris-buffered saline containing $0.1 \%$ Tween and incubated for $2 \mathrm{~h}$ at room temperature with a horseradish peroxidase-conjugated goat anti-rabbit (catalog no. 7074; 1:1000; Cell Signaling Technology, Inc.) or anti-mouse secondary antibody (catalog no. sc-516102, 1:2000, Santa Cruz Biotechnology). Proteins were visualized using a Bio-Rad ChemiDoc Imaging system (Bio-Rad Laboratories, Inc., Hercules, CA, USA).
Statistical analysis. Statistical analysis was performed using Prism 5 software (GraphPad Software, Inc., La Jolla, CA, USA) and SPSS version 16.0 (SPSS, Inc., Chicago, IL, USA). Data are expressed as the mean \pm standard error of three independent experiments. Two-way ANOVA followed by Bonferroni correction was used to determine the statistical significance when the number of groups was more than three. The methylation and expression levels of PTPRO in tumors and healthy controls were compared using paired-samples t-test. The overall survival of LSCC patients were analyzed using the Log-rank test. All tests were two sided and $\mathrm{P}<0.05$ was considered to indicate a statistically significant difference.

\section{Results}

CpG island of PTPRO exon 1 is hypermethylated in LSCC cells and tissues. As the methylation status of PTPRO in LSCC cells is unclear, a BSP assay was performed in H520 and SK-MES-1 cells, and BEAS-2B cells served as a healthy control. As presented in Fig. $1 \mathrm{~A}$ and $\mathrm{B}$, the $\mathrm{CpG}$ island in the 1st exon was hypermethylated in H520 and SK-MES-1 cells, while partially methylated in BEAS-2B cells. Following this, the methylation status of PTPRO in LSCC tissues was assessed using the MSP method. The intensity of methylated alleles was noticeably increased compared with unmethylated alleles (Fig. 1C). To assess if a demethylation agent could restore transcriptional activity, LSCC cells were treated with $0,2.5$ or $5 \mu \mathrm{M} 5$-AZA for $72 \mathrm{~h}$. The mRNA expression levels of PTPRO were significantly increased following 5-AZA treatment in all groups except the $2.5 \mu \mathrm{M}$ treatment group in SK-MES-1 cells (Fig. 1D). These data demonstrated that the CpG island of PTPRO exon 1 was hypermethylated in LSCC cells and tissues, suggesting that the epigenetic regulation of PTPRO may serve a role in LSCC tumorigenesis.

PTPRO is epigenetically downregulated in LSCC tissues. To understand the methylation and mRNA levels of PTPRO, QMSP and RT-qPCR analyses were performed in LSCC and matched healthy tissues. The methylation levels of PTPRO were significantly increased in LSCC tissues compared with healthy controls $(0.0438 \pm 0.0263$ vs. $0.0381 \pm 0.0264 ; \mathrm{P}=0.0005$; Fig. 2A). The mean methylation level of PTPRO in tumors was used as cut-off to divide cases into two groups (high- or low-methylation). A low level of PTPRO methylation was significantly associated with high overall survival probability in LSCC patients ( $\mathrm{P}=0.027$; Fig. 2B). Furthermore, the mRNA expression levels of PTPRO were markedly reduced in tumors compared with healthy tissues $(66.87 \pm 12.11$ vs. $68.24 \pm 11.81$; $\mathrm{P}=0.005$; Fig. 2C), and low expression of PTPRO $(<$ the mean of mRNA levels of PTPRO in tumors) was associated with poor prognosis of patients $(\mathrm{P}=0.002$; Fig. 2D). Pearson correlation coefficient analysis identified an inverse correlation between methylation and mRNA levels of PTPRO in tumors (Pearson $\mathrm{r}=-0.409$; $\mathrm{P}=0.0007$; Fig. 2E).

Subsequently, the present study verified whether the methylation or expression of PTPRO was associated with clinicopathological features of patients. As presented Table I, mRNA expression levels of PTPRO were significantly reduced in advanced tumors compared with early-stage tumors $(\mathrm{P}=0.042)$. The methylation or mRNA levels of PTPRO were not associated 
A

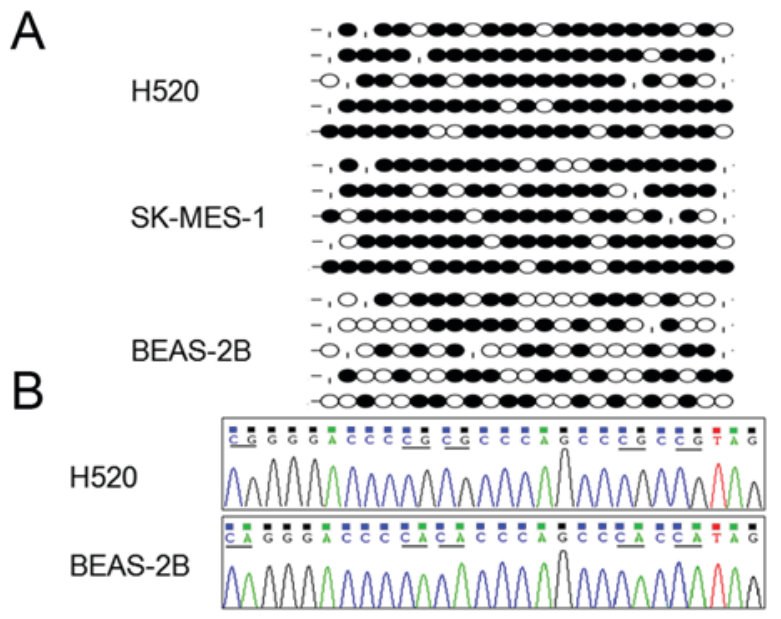

C

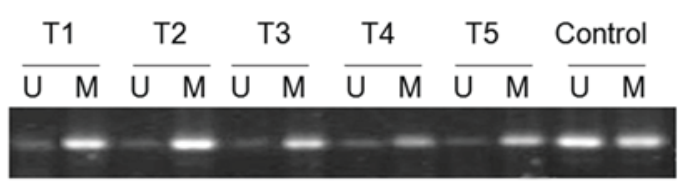

D

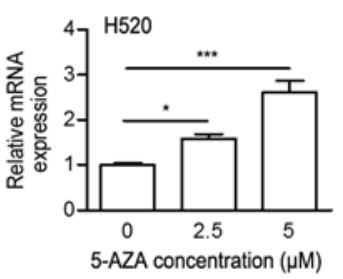

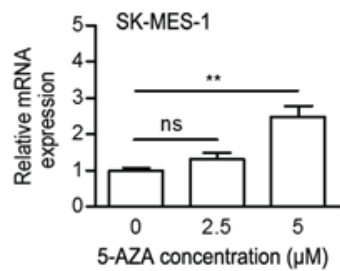

Figure 1. CpG island of the PTPRO promoter (from -405 to -74) is hypermethylated in LSCC cells. (A) Dot graph of BSP data in H520 and SK-MES-1 LSCC cells and BEAS-2B healthy control cells. The BSP-tested region contained $23 \mathrm{CpG}$ sites. Black dot, methylated; white dot, unmethylated; stub, not available. (B) Representative sequences of BSP in H520 and BEAS-2B cells. (C) Methylation-specific polymerase chain reaction of PTPRO in five LSCC tissues. M, methylation alleles; U, unmethylation alleles. (D) Reverse transcription-quantitative polymerase chain reaction analysis of PTPRO mRNA expression levels after $0,2.5$ or $5 \mu \mathrm{M}$ 5-AZA treatment for $72 \mathrm{~h}$. Data are presented as the mean \pm standard deviation. ${ }^{*} \mathrm{P}<0.05 ;{ }^{* * *} \mathrm{P}<0.01 ;{ }^{* * * *} \mathrm{P}<0.001$. ns, non-significant; 5AZA, 5-Aza-2'-deoxycytidine; BSP, bisulfite sequencing; LSCC, lung squamous cell carcinoma, PTPRO, protein tyrosine phosphatase receptor-type O.

A

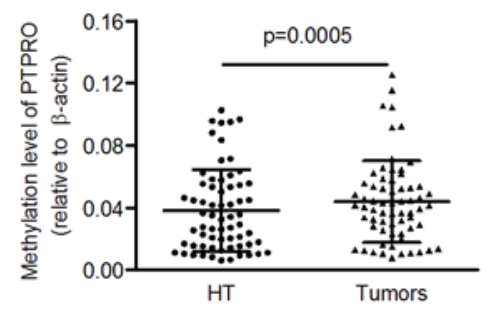

B

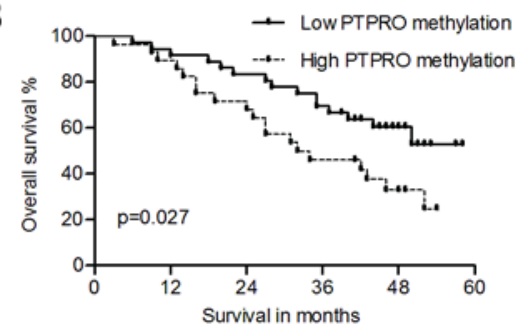

C

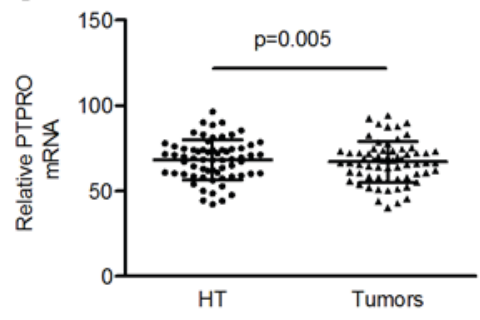

D

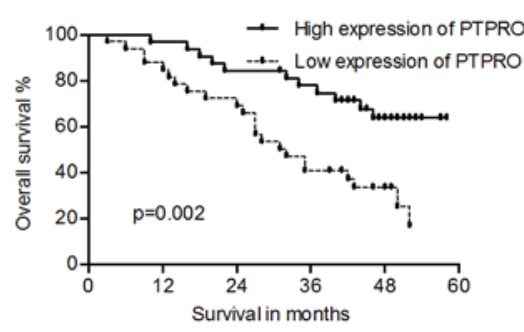

E

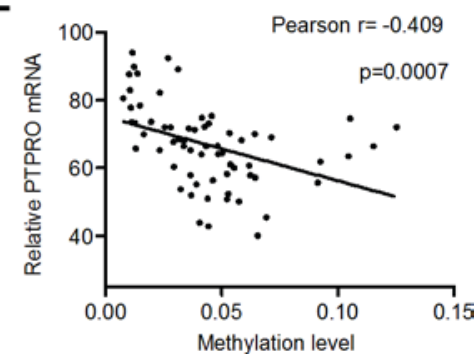

Figure 2. Methylation and expression levels of PTPRO in 65 LSCC tissues and adjacent healthy tissues. (A) Quantitative methylation-specific polymerase chain reaction analysis of PTPRO demonstrated that the methylation level of PTPRO was significantly increased in tumors. (B) Higher PTPRO methylation levels in patients predicted poor prognosis. (C) The mRNA expression levels of PTPRO were detected in tumors or matched healthy tissue by reverse transcription-quantitative polymerase chain reaction. (D) Overall survival analysis indicated that reduced PTPRO mRNA expression levels in patients was associated with poor prognosis. (E) Expression of PTPRO was inversely correlated with its methylation in tumors. Data are presented as the mean \pm standard deviation. HT, healthy tissues; LSCC, lung squamous cell carcinoma, PTPRO, protein tyrosine phosphatase receptor-type O.

with other clinical parameters (Table I). Univariate analysis demonstrated that the high methylation of PTPRO, low PTPRO mRNA, smoking, advanced tumor stage, higher T stage and lymph node metastasis were predictors of poor prognosis for patients, whereas only mRNA expression levels of PTPRO $(\mathrm{P}=0.005)$ and higher TNM stage $(\mathrm{P}=0.001)$ were identified as significantly independent prognostic factors in multivariate analysis, with relative risks of 2.826 and 3.714, respectively (Table II). Taken together, these data suggested that epigenetically downregulated PTPRO may be involved in LSCC development and may be a potential prognostic marker. Detailed clinical and molecular data of the patients are presented in Table III.
PTPRO inhibits cell viability in vitro. The expression levels of PTPRO in transfected cells and control cells were detected. The mRNA (Fig. 3A) and protein (Fig. 3B) expression levels of $P T P R O$ were upregulated in H520 and SK-MES-1 cells transfected with stably expressing $P T P R O$ vectors in comparison with control cells and non-transfected cells. The results of MTT demonstrated that when compared with the empty vector group (control) and non-transfected group (untreated), the proliferation of LSCC cells was significantly inhibited in overexpressing PTPRO cells (Fig. 3C). Colony formation assay was performed to evaluate the effect of $P T P R O$ on LSCC cells. As a result, the number of colonies were significantly reduced in 
Table I. Associations between clinicopathological features and methylation or mRNA expression levels of PTPRO in lung squamous cell carcinoma.

\begin{tabular}{|c|c|c|c|c|c|}
\hline Variable & Total $(n=65)$ & PTPRO Methylation & P-value & PTPRO mRNA & P-value \\
\hline Gender & & & 0.322 & & 0.249 \\
\hline Female & 25 & $0.0471 \pm 0.0254$ & & $64.69 \pm 12.13$ & \\
\hline Male & 40 & $0.0417 \pm 0.0269$ & & $68.23 \pm 12.04$ & \\
\hline Age (years) & & & 0.126 & & 0.133 \\
\hline$<60$ & 28 & $0.0389 \pm 0.0264$ & & $69.11 \pm 13.26$ & \\
\hline$\geq 60$ & 37 & $0.0475 \pm 0.0259$ & & $65.17 \pm 11.04$ & \\
\hline Smoking & & & 0.896 & & 0.788 \\
\hline Never & 31 & $0.0411 \pm 0.0201$ & & $67.33 \pm 12.51$ & \\
\hline Past, current & 34 & $0.0462 \pm 0.0309$ & & $66.44 \pm 11.90$ & \\
\hline TNM stage & & & 0.237 & & 0.042 \\
\hline I, II & 34 & $0.0396 \pm 0.0233$ & & $70.55 \pm 12.49$ & \\
\hline III, IV & 31 & $0.0484 \pm 0.0289$ & & $62.82 \pm 10.42$ & \\
\hline pT stage & & & 0.703 & & 0.603 \\
\hline $\mathrm{T} 1-2$ & 43 & $0.0429 \pm 0.0261$ & & $67.56 \pm 13.13$ & \\
\hline T3-4 & 22 & $0.0455 \pm 0.0271$ & & $65.51 \pm 9.955$ & \\
\hline pN stage & & & 0.263 & & 0.286 \\
\hline No & 17 & $0.0374 \pm 0.0222$ & & $70.64 \pm 3.001$ & \\
\hline N1-3 & 48 & $0.0461 \pm 0.0274$ & & $65.53 \pm 1.711$ & \\
\hline
\end{tabular}

Never, no smoking history; Past, stopped smoking for <1 year; current, current smoker; SD, standard deviation; TNM, tumor node metastasis; PTPRO, protein tyrosine phosphatase receptor-type O.

Table II. Clinical characteristics of lung squamous cell carcinoma patients correlates with overall survival.

\begin{tabular}{|c|c|c|c|c|c|c|}
\hline \multirow[b]{2}{*}{ Variable } & \multicolumn{3}{|c|}{ Univariate analysis } & \multicolumn{3}{|c|}{ Multivariate analysis } \\
\hline & $\mathrm{HR}$ & $95 \% \mathrm{CI}$ & P-value & HR & $95 \% \mathrm{CI}$ & P-value \\
\hline PTPRO methylation (low/high) & 2.108 & $1.068-4.163$ & 0.032 & & & \\
\hline PTPRO mRNA (high/low) & 2.971 & $1.442-6.121$ & 0.003 & 2.826 & $1.364-5.853$ & 0.005 \\
\hline Gender (female/male) & 1.15 & $0.569-2.326$ & 0.696 & & & \\
\hline Age $(<60 \mathrm{y} / \geq 60 \mathrm{y})$ & 1.037 & $0.991-1.085$ & 0.119 & & & \\
\hline Smoking (never/past, current) & 2.113 & $1.042-4.286$ & 0.038 & & & \\
\hline TNM stage (I, II/III, IV) & 4.145 & $1.998-8.061$ & 0.000 & 3.714 & $1.771-7.792$ & 0.001 \\
\hline T stage (T1-2/T3-4) & 2.288 & $1.149-4.555$ & 0.018 & & & \\
\hline N stage (N0/N1-3) & 2.743 & $1.060-7.101$ & 0.038 & & & \\
\hline
\end{tabular}

HR, hazard ratio; CI, confidence interval; TNM, tumor node metastasis; PTPRO, protein tyrosine phosphatase receptor-type O.

H520 and SK-MES-1 cells transfected with PTPRO expressing vectors, compared with control and untreated cells (Fig. 3D). These in vitro analyses demonstrated the inhibitory effect of PTPRO on cell viability.

PTPRO impairs the tumorigenicity of H520 cells in vivo. The inhibitory role of PTPRO was further confirmed using a xenograft model of H520 cells in nude mice. As expected, there was a significant reduction in tumor volume and weight in the PTPRO overexpression group compared with the empty vector group (Fig. 4A and B). In addition, mRNA expression levels of PTPRO were upregulated in tumors injected with PTPRO vectors (Fig. 4C).

\section{Discussion}

Many LSCC patients are already in the advanced stages when diagnosed, rendering treatment difficult. The initiation and progression of squamous cell carcinoma is a complex process involving the abnormalities of a variety of oncogenes and tumor suppressors $(26,27)$. The present study focused on the novel tumor suppressor PTPRO. 
Table III. Detailed clinical and molecular data of cases.

\begin{tabular}{|c|c|c|c|c|c|c|c|c|c|c|}
\hline IID & Methy (H) & Methy (T) & $\operatorname{mRNA}(\mathrm{H})$ & $\operatorname{mRNA}(\mathrm{T})$ & Gender & Age & Smoking & TNM & Survival & Months \\
\hline 1 & 0.0416 & 0.0445 & 78.02 & 73.09 & M & 57 & current & T3N2M0 & No & 16 \\
\hline 2 & 0.0253 & 0.0384 & 71.13 & 71.283 & M & 66 & current & T1N2M0 & No & 32 \\
\hline 3 & 0.0553 & 0.0623 & 56.214 & 57.89 & M & 45 & past & T3N0M0 & No & 52 \\
\hline 4 & 0.0363 & 0.0487 & 67.083 & 64.097 & $\mathrm{~F}$ & 61 & never & T2N0M0 & Yes & 52 \\
\hline 5 & 0.00652 & 0.0149 & 79.032 & 78.37 & M & 55 & current & T1N1M0 & Yes & 50 \\
\hline 6 & 0.0272 & 0.0368 & 57.734 & 51.98 & M & 59 & never & $\mathrm{T} 2 \mathrm{~N} 1 \mathrm{M} 0$ & No & 50 \\
\hline 7 & 0.0966 & 0.1252 & 76.04 & 72.01 & M & 58 & current & T1N2M0 & Yes & 54 \\
\hline 8 & 0.0357 & 0.0427 & 74.32 & 72.094 & $\mathrm{M}$ & 72 & never & T3N0M0 & Yes & 41 \\
\hline 9 & 0.0623 & 0.0619 & 52.77 & 60.67 & $\mathrm{~F}$ & 64 & never & T3N0M0 & Yes & 41 \\
\hline 10 & 0.0422 & 0.0534 & 74.04 & 70.32 & M & 62 & never & $\mathrm{T} 2 \mathrm{~N} 1 \mathrm{M} 0$ & Yes & 43 \\
\hline 11 & 0.0342 & 0.0415 & 68.32 & 74.89 & M & 59 & never & $\mathrm{T} 2 \mathrm{~N} 1 \mathrm{M} 0$ & No & 44 \\
\hline 12 & 0.0164 & 0.0268 & 96.43 & 92.384 & M & 60 & current & T1N1M0 & Yes & 51 \\
\hline 13 & 0.1026 & 0.1154 & 69.05 & 66.391 & $\mathrm{M}$ & 66 & current & T4N1M0 & No & 19 \\
\hline 14 & 0.0949 & 0.1045 & 60.21 & 63.42 & $\mathrm{~F}$ & 68 & current & T1N1M0 & No & 42 \\
\hline 15 & 0.0713 & 0.0643 & 70.14 & 70.06 & M & 72 & past & $\mathrm{T} 2 \mathrm{~N} 2 \mathrm{M} 0$ & No & 34 \\
\hline 16 & 0.0532 & 0.0503 & 60.69 & 64.382 & $\mathrm{M}$ & 68 & current & T3N2M0 & No & 13 \\
\hline 17 & 0.0106 & 0.0483 & 66.985 & 66.45 & $\mathrm{~F}$ & 55 & never & $\mathrm{T} 2 \mathrm{~N} 2 \mathrm{M} 0$ & Yes & 52 \\
\hline 18 & 0.0214 & 0.0312 & 84.376 & 89.103 & $\mathrm{~F}$ & 53 & never & T1N0M0 & Yes & 47 \\
\hline 19 & 0.0123 & 0.0164 & 62.165 & 70.01 & $\mathrm{~F}$ & 62 & never & $\mathrm{T} 2 \mathrm{~N} 2 \mathrm{M} 0$ & Yes & 57 \\
\hline 20 & 0.0226 & 0.0324 & 58.54 & 53.75 & M & 64 & current & T1N1M0 & No & 12 \\
\hline 21 & 0.0351 & 0.0456 & 81.23 & 75.376 & $\mathrm{~F}$ & 59 & never & $\mathrm{T} 2 \mathrm{~N} 1 \mathrm{M} 0$ & Yes & 49 \\
\hline 22 & 0.0556 & 0.0575 & 44.01 & 50.09 & $\mathrm{~F}$ & 77 & never & T3N1M1 & No & 16 \\
\hline 23 & 0.0434 & 0.0537 & 62.93 & 61.067 & M & 62 & past & T1N2M0 & No & 24 \\
\hline 24 & 0.0153 & 0.0292 & 72.71 & 67.651 & M & 69 & never & T3N1M0 & Yes & 49 \\
\hline 25 & 0.0441 & 0.0439 & 59.92 & 51.06 & M & 68 & current & T3N1M0 & No & 25 \\
\hline 26 & 0.0532 & 0.0528 & 54.04 & 52.39 & $\mathrm{~F}$ & 72 & never & T2N0M0 & Yes & 9 \\
\hline 27 & 0.0503 & 0.0645 & 60.87 & 57.09 & $\mathrm{~F}$ & 75 & never & T1N1M0 & No & 48 \\
\hline 28 & 0.0413 & 0.0392 & 58.36 & 55.09 & $\mathrm{~F}$ & 55 & never & T1N0M0 & Yes & 46 \\
\hline 29 & 0.0096 & 0.0126 & 74.09 & 73.213 & $\mathrm{M}$ & 67 & current & T2N0M0 & Yes & 47 \\
\hline 30 & 0.0634 & 0.0714 & 73.98 & 69.08 & $\mathrm{M}$ & 63 & past & $\mathrm{T} 2 \mathrm{~N} 1 \mathrm{M} 0$ & No & 46 \\
\hline 31 & 0.00921 & 0.0105 & 85.362 & 82.99 & $\mathrm{M}$ & 62 & current & $\mathrm{T} 2 \mathrm{~N} 1 \mathrm{M} 0$ & Yes & 42 \\
\hline 32 & 0.04632 & 0.0443 & 50.093 & 42.78 & $\mathrm{~F}$ & 63 & never & T1N2M0 & No & 27 \\
\hline 33 & 0.02752 & 0.03648 & 59.986 & 57.853 & $\mathrm{M}$ & 67 & current & T3N2M0 & Yes & 39 \\
\hline 34 & 0.0264 & 0.0336 & 70.84 & 67.895 & $\mathrm{~F}$ & 77 & never & T1N1M0 & Yes & 52 \\
\hline 35 & 0.0144 & 0.0293 & 63.468 & 60.432 & M & 57 & past & $\mathrm{T} 2 \mathrm{~N} 2 \mathrm{M} 0$ & Yes & 49 \\
\hline 36 & 0.01123 & 0.01293 & 64.35 & 65.783 & M & 65 & current & $\mathrm{T} 2 \mathrm{~N} 3 \mathrm{M} 0$ & No & 9 \\
\hline 37 & 0.0261 & 0.0359 & 67.94 & 71.67 & M & 53 & current & T1N0M0 & No & 40 \\
\hline 38 & 0.0292 & 0.0366 & 68.17 & 65.332 & $\mathrm{~F}$ & 73 & never & T3N1M0 & No & 35 \\
\hline 39 & 0.0061 & 0.0077 & 81.653 & 80.56 & $\mathrm{M}$ & 58 & past & T2N0M0 & Yes & 48 \\
\hline 40 & 0.04493 & 0.0523 & 60.41 & 58.24 & $\mathrm{~F}$ & 70 & never & T3N1M1 & No & 3 \\
\hline 41 & 0.0236 & 0.0413 & 68.56 & 64.02 & $\mathrm{~F}$ & 52 & never & $\mathrm{T} 2 \mathrm{~N} 1 \mathrm{M} 0$ & Yes & 46 \\
\hline 42 & 0.0958 & 0.0914 & 59.054 & 55.67 & $\mathrm{~F}$ & 64 & current & T1N2M0 & No & 14 \\
\hline 43 & 0.0142 & 0.0317 & 71.23 & 68.541 & M & 66 & current & $\mathrm{T} 2 \mathrm{~N} 2 \mathrm{M} 0$ & No & 22 \\
\hline 44 & 0.01116 & 0.01157 & 90.01 & 94.03 & $\mathrm{M}$ & 55 & past & T1N0M0 & Yes & 58 \\
\hline 45 & 0.08357 & 0.01094 & 78.55 & 77.83 & $\mathrm{~F}$ & 59 & never & T3N1M0 & Yes & 48 \\
\hline 46 & 0.0607 & 0.0555 & 61.64 & 60.098 & M & 51 & never & T3N1M0 & No & 32 \\
\hline 47 & 0.0578 & 0.0586 & 71.62 & 68.154 & $\mathrm{M}$ & 53 & current & $\mathrm{T} 1 \mathrm{~N} 1 \mathrm{M} 0$ & Yes & 31 \\
\hline 48 & 0.0545 & 0.0523 & 57.43 & 50.82 & M & 64 & current & T1N1M0 & Yes & 43 \\
\hline 49 & 0.0945 & 0.1054 & 76.841 & 74.54 & $\mathrm{~F}$ & 69 & never & T3N2M0 & Yes & 10 \\
\hline 50 & 0.0582 & 0.0693 & 48.68 & 45.469 & $\mathrm{M}$ & 60 & never & T3N2M0 & No & 9 \\
\hline 51 & 0.00843 & 0.01128 & 74.71 & 73.52 & $\mathrm{M}$ & 55 & past & T3N1M0 & Yes & 45 \\
\hline 52 & 0.0446 & 0.0431 & 73.12 & 66.376 & $\mathrm{~F}$ & 68 & never & T1N0M0 & No & 35 \\
\hline
\end{tabular}


Table III. Continued.

\begin{tabular}{lllllllllll}
\hline IID & Methy $(\mathrm{H})$ & Methy $(\mathrm{T})$ & mRNA $(\mathrm{H})$ & mRNA $(\mathrm{T})$ & Gender & Age & Smoking & TNM & Survival & Months \\
\hline 53 & 0.0882 & 0.0925 & 64.89 & 61.87 & $\mathrm{M}$ & 56 & current & T2N0M0 & Yes & 46 \\
54 & 0.00948 & 0.01237 & 88.56 & 89.82 & $\mathrm{~F}$ & 59 & never & T1N1M0 & Yes & 46 \\
55 & 0.01512 & 0.02538 & 73.02 & 72.02 & $\mathrm{M}$ & 78 & past & T3N2M0 & No & 18 \\
56 & 0.0197 & 0.0336 & 69.332 & 66.365 & $\mathrm{M}$ & 63 & never & T3N0M0 & No & 27 \\
57 & 0.0703 & 0.0655 & 42.24 & 40.08 & $\mathrm{~F}$ & 58 & current & T1N2M0 & No & 31 \\
58 & 0.01692 & 0.02335 & 83.01 & 82.32 & $\mathrm{M}$ & 64 & never & T1N0M0 & Yes & 52 \\
59 & 0.01808 & 0.04049 & 44.33 & 43.9 & $\mathrm{M}$ & 47 & current & T2N1M1 & No & 6 \\
60 & 0.0156 & 0.01964 & 74.841 & 73.546 & $\mathrm{~F}$ & 57 & never & T3N2M0 & Yes & 37 \\
61 & 0.00938 & 0.01015 & 90.091 & 87.569 & $\mathrm{M}$ & 50 & never & T2N1M0 & Yes & 53 \\
62 & 0.02085 & 0.02322 & 71.841 & 65.323 & $\mathrm{~F}$ & 52 & past & T3N0M0 & No & 28 \\
63 & 0.0203 & 0.02813 & 73.841 & 72.04 & $\mathrm{~F}$ & 59 & current & T2N2M0 & No & 20 \\
64 & 0.03256 & 0.0463 & 47.65 & 56.33 & $\mathrm{M}$ & 52 & current & T2N3M0 & No & 27 \\
65 & 0.01014 & 0.01379 & 83.01 & 87.83 & $\mathrm{M}$ & 62 & never & T3N0M0 & Yes & 49 \\
\hline
\end{tabular}

Methy $(\mathrm{H})$, methylation levels in healthy tissues; Methy $(\mathrm{T})$, methylation levels in tumors; mRNA $(\mathrm{H})$, mRNA levels in healthy tissues; mRNA (T), mRNA levels in tumors; F, female; M, male; Months, survival in months; TNM, tumor node metastasis.

A

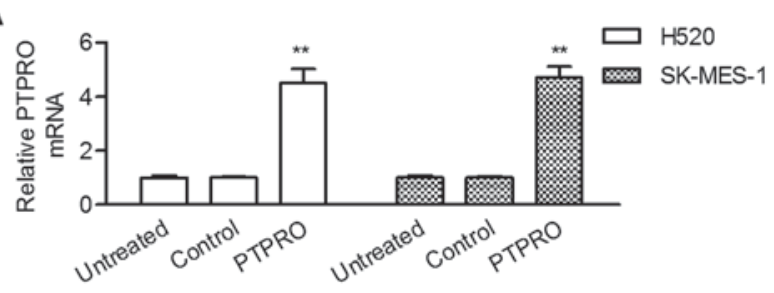

B

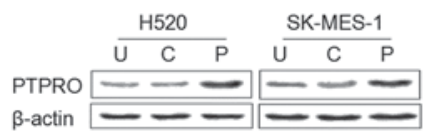

C
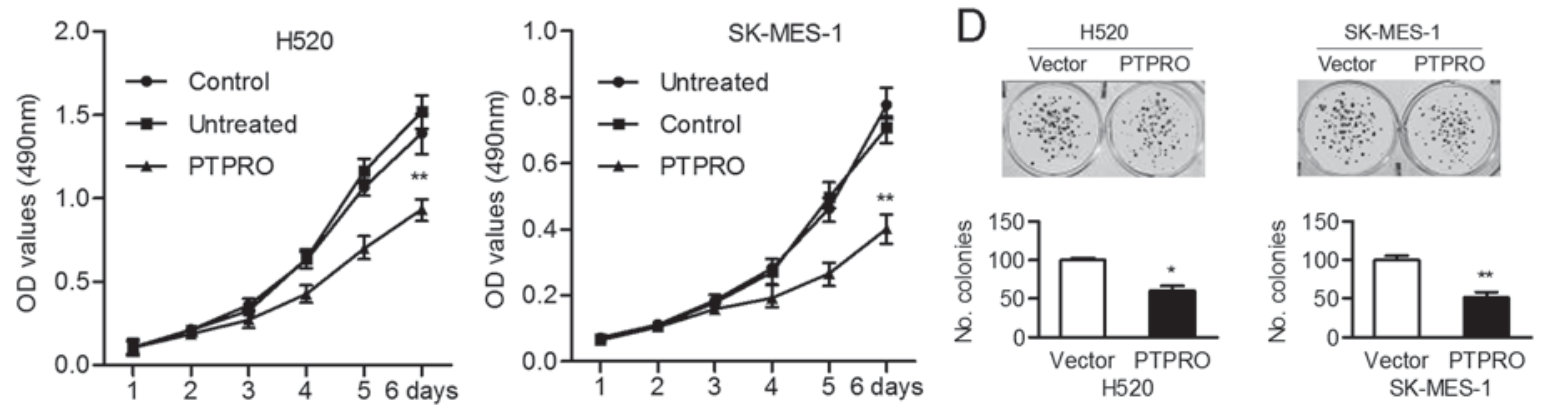

Figure 3. Overexpression of PTPRO inhibits LSCC cell growth in vitro. (A) The mRNA expression levels of PTPRO were markedly increased following transfection with a pcDNA-PTPRO vector. (B) The protein expression levels of PTPRO were detected by western blotting. (C) The effect of PTPRO on cell proliferation was measured by MTT assay. (D) Representative micrographs and quantification of stained H520 and SK-MES-1 cell colonies. Data are presented as the mean \pm standard deviation. ${ }^{*} \mathrm{P}<0.05 ;{ }^{* *} \mathrm{P}<0.01$. LSCC, lung squamous cell carcinoma, $\mathrm{PTPRO}$, protein tyrosine phosphatase receptor-type $\mathrm{O}$; OD, optical density; U, untreated; C, control; P, PTPRO.

A

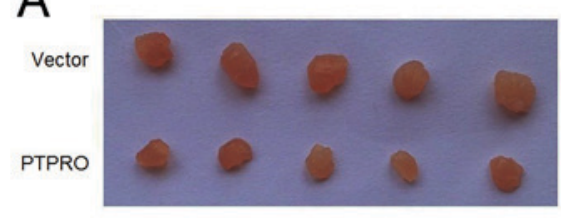

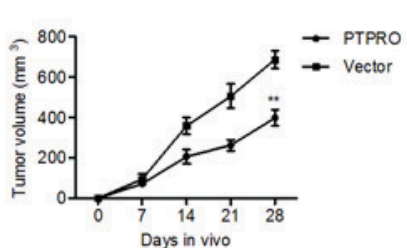

B
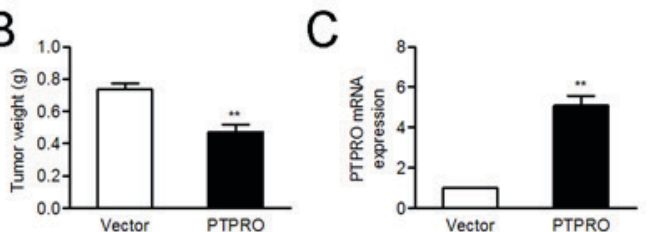

Figure 4. PTPRO inhibits tumor growth in vivo. (A) pcDNA-PTPRO- and control vector- transfected H520 cells were injected subcutaneously into the flanks of nude mice. Tumor volumes were measured every 7 days. Tumor volumes was significantly reduced in tumors stably expressing PTPRO. (B) Tumor weight was calculated at 4 weeks post injection. (C) mRNA expression levels of PTPRO in xenograft tumors were confirmed by reverse transcription-quantitative polymerase chain reaction. Data are presented as the mean \pm standard deviation. ${ }^{* *} \mathrm{P}<0.01$. PTPRO, protein tyrosine phosphatase receptor-type $\mathrm{O}$. 
It is well known that the cell tyrosine phosphorylation levels are co-regulated by PTP and protein tyrosine kinase (PTK); dysfunction of tyrosine phosphatase is closely associated with the occurrence of a variety of human tumors (28). Previous studies have demonstrated that overexpression of PTP in cancer cells may reverse the malignant transformation induced by PTK (29). PTPRO is a member of the PTP family that has been reported to be frequently methylated, and is characterized as a tumor suppressor gene in the occurrence and development of many malignancies (13-16). The present study examined H520 and SK-MES-1 LSCC cells and LSCC cases for analysis. The CpG island of PTPRO exon1 was revealed to be hypermethylated, which was consistent with previous studies (14). Additionally, in the present study, high methylation or low expression of PTPRO were associated with poor prognosis. Similar results have been reported in breast $(21,30)$ and colorectal $(31)$ cancer. Li et al (30) reported that methylation of PTPRO was an independent predictor for survival. However, mRNA expression of PTPTO, rather than methylation, was an independent factor in the present study. All these data strongly suggested that $P T P R O$ is involved in tumorigenesis and may serve as a valuable prognostic marker in cancers.

Although the function and underlying mechanism of PTPRO has been documented in former studies (18-20), the biological effect of PTPRO in LSCC remains unclear. The present study demonstrated that ectopic PTPRO expression significantly inhibited the proliferation rate and colony formation ability of cells. Previous investigations observed a similar effect in lung adenocarcinoma and lymphoma $(14,19)$. PTPRO was also reported to be involved in other critical biological processes including angiogenesis, metastasis and apoptosis $(18,20,21)$. Therefore, $P T P R O$ may serve as a multi-functional regulator in tumorigenesis. In the present study, tumorigenicity analysis confirmed the tumor suppressive effect of PTPRO in vivo. Taken together, these findings expanded current knowledge of PTPRO in LSCC, suggesting the potential value of $P T P R O$ as a therapeutic target.

In conclusion, the present study demonstrated that $P T P R O$ inhibits tumor growth in vitro and in vivo, indicating the tumor suppressive function of PTPRO in LSCC. This study highlights PTPRO as an epigenetically silenced gene, and a candidate tumor-suppressor of LSCC.

\section{References}

1. Derman BA, Mileham KF, Bonomi PD, Batus M and Fidler MJ: Treatment of advanced squamous cell carcinoma of the lung: A review. Transl Lung Cancer Res 4: 524-532, 2015.

2. Minami $\mathrm{H}$, Isomoto $\mathrm{H}$, Inoue $\mathrm{H}$, Akazawa $\mathrm{Y}$, Yamaguchi $\mathrm{N}$, Ohnita K, Takeshima F, Hayashi T, Nakayama T and Nakao K: Significance of background coloration in endoscopic detection of early esophageal squamous cell carcinoma. Digestion 89: 6-11, 2014.

3. Weißenborn C, Ignatov T, Ochel HJ, Costa SD, Zenclussen AC, Ignatova $\mathrm{Z}$ and Ignatov $\mathrm{A}$ : GPER functions as a tumor suppressor in triple-negative breast cancer cells. J Cancer Res Clin Oncol 140: 713-723, 2014.

4. Calì G, Insabato L, Conza D, Bifulco G, Parrillo L, Mirra P, Fiory F, Miele C, Raciti GA, Di Jeso B, et al: GRP78 mediates cell growth and invasiveness in endometrial cancer. J Cell Physiol 229: 1417-1426, 2014.

5. Tan B, Anaka M, Deb S, Freyer C, Ebert LM, Chueh AC, Al-Obaidi S, Behren A, Jayachandran A, Cebon J, et al: FOXP3 over-expression inhibits melanoma tumorigenesis via effects on proliferation and apoptosis. Oncotarget 5: 264-276, 2014.
6. Correa TC, Brohem CA, Winnischofer SM, da Silva Cardeal LB, Sasahara RM, Taboga SR, Sogayar MC and Maria-Engler SS: Downregulation of the RECK-tumor and metastasis suppressor gene in glioma invasiveness. J Cell Biochem 99: 156-167, 2006.

7. Romagnolo AP, Romagnolo DF and Selmin OI: BRCA1 as target for breast cancer prevention and therapy. Anticancer Agents Med Chem 15: 4-14, 2015.

8. Thaler S, Hähnel PS, Schad A, Dammann R and Schuler M: RASSF1A mediates p21Cip1/Waf1-dependent cell cycle arrest and senescence through modulation of the Raf-MEK-ERK pathway and inhibition of Akt. Cancer Res 69: 1748-1757, 2009.

9. Wang L, Ge J, Ma T, Zheng Y, Lv S, Li Y and Liu S: Promoter hypermethylation of the cysteine protease RECK may cause metastasis of osteosarcoma. Tumour Biol 36: 9511-9516, 2015.

10. Magdinier F, Ribieras S, Lenoir GM, Frappart L and Dante R: Down-regulation of BRCA1 in human sporadic breast cancer; analysis of DNA methylation patterns of the putative promoter region. Oncogene 17: 3169-3176, 1998.

11. Dammann R, Schagdarsurengin U, Strunnikova M, Rastetter M, Seidel C, Liu L, Tommasi S and Pfeifer GP: Epigenetic inactivation of the Ras-association domain family 1 (RASSF1A) gene and its function in human carcinogenesis. Histol Histopathol 18: 665-677, 2003

12. Wiggins RC, Wiggins JE, Goyal M, Wharram BL and Thomas PE: Molecular cloning of cDNAs encoding human GLEPP1, a membrane protein tyrosine phosphatase: Characterization of the GLEPP1 protein distribution in human kidney and assignment of the GLEPP1 gene to human chromosome 12p12-p13. Genomics 27: 174-181, 1995.

13. Motiwala T, Ghoshal K, Das A, Majumder S, Weichenhan D, Wu YZ, Holman K, James SJ, Jacob ST and Plass C: Suppression of the protein tyrosine phosphatase receptor type O gene (PTPRO) by methylation in hepatocellular carcinomas. Oncogene 22 : 6319-6331, 2003

14. Motiwala T, Kutay H, Ghoshal K, Bai S, Seimiya H, Tsuruo T, Suster S, Morrison C and Jacob ST: Protein tyrosine phosphatase receptor-type O (PTPRO) exhibits characteristics of a candidate tumor suppressor in human lung cancer. Proc Natl Acad Sci USA 101: 13844-13849, 2004.

15. Motiwala T, Majumder S, Kutay H, Smith DS, Neuberg DS, Lucas DM, Byrd JC, Grever M and Jacob ST: Methylation and silencing of protein tyrosine phosphatase receptor type $\mathrm{O}$ in chronic lymphocytic leukemia. Clin Cancer Res 13: 3174-3181, 2007.

16. You YJ, Chen YP, Zheng XX, Meltzer SJ and Zhang H: Aberrant methylation of the PTPRO gene in peripheral blood as a potential biomarker in esophageal squamous cell carcinoma patients. Cancer Lett 315: 138-144, 2012.

17. Laczmanska I and Sasiadek MM: Tyrosine phosphatases as a superfamily of tumor suppressors in colorectal cancer. Acta Biochim Pol 58: 467-470, 2011.

18. Hou J, Xu J, Jiang R, Wang Y, Chen C, Deng L, Huang X, Wang $X$ and Sun B: Estrogen-sensitive PTPRO expression represses hepatocellular carcinoma progression by control of STAT3. Hepatology 57: 678-688, 2013.

19. Chen L, Juszczynski P, Takeyama K, Aguiar RC and Shipp MA: Protein tyrosine phosphatase receptor-type O truncated (PTPROt) regulates SYK phosphorylation, proximal B-cell-receptor signaling and cellular proliferation. Blood 108: 3428-3433, 2006.

20. Liu Z, Hou J, Ren L, He J, Sun B, Sun LZ and Wang S: Protein tyrosine phosphatase receptor type $\mathrm{O}$ expression in the tumor niche correlates with reduced tumor growth, angiogenesis, circulating tumor cells and metastasis of breast cancer. Oncol Rep 33: 1908-1914, 2015

21. Yu M,Lin G, Arshadi N, Kalatskaya I, Xue B, Haider S, Nguyen F, Boutros PC, Elson A, Muthuswamy LB, et al: Expression profiling during mammary epithelial cell three-dimensional morphogenesis identifies PTPRO as a novel regulator of morphogenesis and ErbB2-mediated transformation. Mol Cell Biol 32: 3913-3924, 2012.

22. Chien W, Yin D, Gui D, Mori A, Frank JM, Said J, Kusuanco D, Marchevsky A, McKenna R and Koeffler HP: Suppression of cell proliferation and signaling transduction by connective tissue growth factor in non-small cell lung cancer cells. Mol Cancer Res 4: 591-598, 2006.

23. Werstuck GH, Lentz SR, Dayal S, Hossain GS, Sood SK, Shi YY, Zhou J, Maeda N, Krisans SK, Malinow MR and Austin RC: Homocysteine-induced endoplasmic reticulum stress causes dysregulation of the cholesterol and triglyceride biosynthetic pathways. J Clin Invest 107: 1263-1273, 2001. 
24. Jerónimo C, Henrique R, Hoque MO, Ribeiro FR, Oliveira J, Fonseca D, Teixeira MR, Lopes C and Sidransky D: Quantitative RARbeta2 hypermethylation: A promising prostate cancer marker. Clin Cancer Res 10: 4010-4014, 2004.

25. Livak KJ and Schmittgen TD: Analysis of relative gene expression data using real-time quantitative PCR and the 2(-Delta Delta C(T)) Method. Methods 25: 402-408, 2001.

26. Coutinho-Camillo CM, Lourenço SV, de Araújo Lima L, Kowalski LP and Soares FA: Expression of apoptosis-regulating miRNAs and target mRNAs in oral squamous cell carcinoma. Cancer Genet 208: 382-389, 2015.

27. Zhang X, Xu Y, He C, Guo X, Zhang J, He C, Zhang L, Kong M, Chen B and Zhu C: Elevated expression of CCAT2 is associated with poor prognosis in esophageal squamous cell carcinoma. J Surg Oncol 111: 834-839, 2015.
28. Jacob ST and Motiwala T: Epigenetic regulation of protein tyrosine phosphatases: Potential molecular targets for cancer therapy. Cancer Gene Ther 12: 665-672, 2005.

29. Matozaki T and Kasuga M: Roles of protein-tyrosine phosphatases in growth factor signalling. Cell Signal 8: 13-19, 1996.

30. Li SY, Li R, Chen YL, Xiong LK, Wang HL, Rong L and Luo RC: Aberrant PTPRO methylation in tumor tissues as a potential biomarker that predicts clinical outcomes in breast cancer patients. BMC Genet 15: 67, 2014.

31. Asbagh LA, Vazquez I, Vecchione L, Budinska E, De Vriendt V, Baietti MF, Steklov M, Jacobs B, Hoe N, Singh S, et al: The tyrosine phosphatase PTPRO sensitizes colon cancer cells to anti-EGFR therapy through activation of SRC-mediated EGFR signaling. Oncotarget 5: 10070-10083, 2014. 